\title{
Creating Living and Learning Community on a Diverse College Campus
}

\author{
Xiaoyuan Wang \\ Shanghai University of Engineering and Science, Shanghai 201600, China \\ xiaoyuan_wang@126.com
}

Keywords: diversity, living and learning community, intergroup dialogue, sense of belonging, critical thinking, ethnocentrism

Abstract: In order to provide a well-rounded education for college students, diversity on campus plays an important role. Establishing an environment which broadens a student's perspective has been determined by universities and colleges by increasing the amounts of diversity among their campuses. In order for students to gain a diverse education and benefit, the institution must support and believe the benefits of a diverse education as well by providing support for diversity on campus through its programs and activities. This study focus on creating a living and learning community designed for targeted groups on a diverse college campus, which creating an environment outside of the classroom for students taking a common course and live in close physical proximity, increases interactions outside of classes. A living-learning community instills a sense of belonging, foster an appreciation and understanding of diversity, and provide skills to enhance student ability to effectively work with diverse individuals. We propose a systematic and careful documentation and evaluation process of the program from beginning to end which evaluate what effect this program has on participants and whether and how dialogue achieves desired goals.

\section{Diversity among higher education}

Students entering into college today are the most "racially and ethnically diverse in this nation's history" [3]. Diversity among higher education will continue to play an intricate part in the daily lives of college students as well as others who contribute to campus society. Students state (Light, 2001) that there are two parts to take into consideration when discussing diversity on campus, access and educational impact. The first part, access, "do students who have different backgrounds have the opportunity to attend any college" [15]. The second part, educational impact, asks, "What is the impact, educationally and personally, on students from all ethnic and racial backgrounds, of attending college with fellow students from diverse backgrounds" [15]. When discussing the importance of a diverse learning environment, students make it a point to say "how well ethnic and racial diversity actually enhances learning depends largely on how well a college builds on, capitalizes on, and proactively strengthens this basic assumption” [15]. Overall, many students feel that in order to receive a well-rounded education, diversity on campus plays an important role. 


\section{The benefits of diversity in education and the importance of forming diverse community}

Students entering into college are looking for the overall college experience and diversity has an impact on these decisions. Research has been done regarding diversity within higher education. Specifically, research regarding the benefits of receiving a diverse education. Studies have been done assessing the effects of a diverse learning environment and students' thoughts. By enhancing curriculum and interactions with a diverse classroom setting, students will gain intellect and active thinking skills.

Establishing an environment which broadens a student's perspective has been determined by universities and colleges by increasing the amounts of diversity among their campuses. The issue of diversity has longed been valued as important among campuses. "Diverse views are the backbone of universities, for they stimulate new ideas and creations" [4]. Dating back to the Socratic tradition, the belief was "knowledge or understanding flourishes best in a climate of vigorous debate" [4] .This still holds true today when examining multiculturalism within a structured learning environment. Some research suggests that students will gain a diverse education by just being placed within a diverse setting. There is no assurance of a student's willingness to participate in diversity [19] .For some students they follow the same pattern that they have followed their whole lives which is staying within their comfort zones. According to Milem, Chang, and Antonio (2005), it is important to form interracial friendships in order to have an interracial campus. Many studies have shown that by having close friends of a different race or ethnicity is "a powerful way in which students accrues the education benefits of diversity" [19]. According to Melissa Paquette and Barbara Schlafer in their article, The Many Benefits of a Diverse Campus Community (2005), students who hail from a racially and ethnically diverse student body, they "learn better, think deeper, and are better prepared to become active participants in society once they leave school” [25]. Research also suggests that in order for students to gain a diverse education and benefit, the institution must support and believe in these benefits as well. By providing support for diversity on campus through its programs and activities, institutions can begin to show that they believe in the benefits of a diverse education.

\section{Introduction of Living and Learning Community}

A sense of community is an important factor in a college student's experience. This means they have "a feeling that members have of belonging, a feeling that members matter to one another and to the group, and a shared faith that members' need will be met” [17]. Having a sense of community is vital to mental health. Learning communities have a different effect on various ethnicities. Meeuwisse, Severiens, and Born (2010) found that "a sense of belonging primarily predicted academic progress for White students where as others found that sense of belonging was linked to student persistence among White, African American, and Latino students. ” [29]

Many institutions create residence hall environments to promote learning and development. These are typically called residential learning communities or living learning communities [24]. Living learning communities are designed to improve faculty-student interaction, create a more supportive peer climate, and to assist students in integrating diverse curricular and cocurricular experiences [16, 26, 27].

Learning communities have four forms according to Lenning and Ebbers (1999): They are made up of students co-enrolled in two or more curricular courses that are linked by a common theme. Learning communities treat a classroom as a place for community building and cooperative learning activities. Living learning communities create an environment outside of the classroom for students taking two or more common courses to live in close physical proximity, this increases interactions 
outside of classes. Lastly, learning communities are designed for targeted groups; this includes underprepared students, underrepresented students, honors students, students with disabilities, or students of different backgrounds and cultures.

In 1994, the American College Personnel Association (ACPA) stressed the importance of linking students' in class and out of class experiences to create a more seamless learning environment that focused on academic success and student learning [24]. He adds that is it essential to enhance students' educational and overall development and it encourages students to "devote more time to educationally purposeful activities both in and outside of the classroom [7]. Chickering (1975) argued that student development requires differentiation and integration. Differentiation is fostered when students are introduced to a variety of academic disciplines that will have meaningful out-of-class experiences and chances for students to interact with people of different backgrounds and cultures than that of their own. He also stated that students must be able to see relationships among diverse experiences to solve various complex problems [12].

Schroeder and Mable (1994) state that residential halls provide experiences to bring together students and so they may make gains in their learning and intellectual development. Students spend a significant amount of time in their residence halls and opportunities for student interaction and to be involved in out of class activities. Students who live off campus tend to have less levels of involvement in activities that are outside of class [9, 12, 22]. Residential halls represent a strong venue for integrating diverse curricular and cocurricular experiences [16].

\section{Living and Learning Community Initiative}

A living-learning community instills a sense of belonging, foster an appreciation and understanding of diversity, and provide skills to enhance student ability to effectively work with diverse individuals. To develop such a community, all students participating in the initiative will reside in a hall and enroll in a course which called "Introduction to Intergroup Dialogue". Living in the same hall and taking the same course will allow the same students to interact in academic and nonacademic settings. Additionally, the course will engage students in meaningful discussions about social identity, conflict, community, and social justice. This residential and curricular combination will unite students through shared experiences and provide a safe place to explore and understand their differences and work across them. Throughout one year, the student hall will reinforce the themes of identity exploration, conflict resolution, sense of community, and social justice through workshops, events, and student leadership opportunities.

The university will primarily use New Student Orientation to recruit students to participate in the project. Every student attending the student orientation will attend a session introducing the living and learning and how to apply. Application materials will be available during this time. Information and application materials will also appear on the website. Any first- or second-year student interested in advancing diversity awareness and understanding can apply. As part of the application students must include a statement of their commitment to diversity and inclusion. To help create and assign the course "Introduction to Intergroup Dialogue", students will list their five most salient social identities. All students who apply and meet the requirements will be accepted.

Students participating take the course "Introduction to Intergroup Dialogue" during the first five weeks of the fall semester. This class will be tuition-free, one credit hour, and count toward graduation requirements. Each section will meet two times a week for an hour and a half. Two instructors co-facilitate each section. Each section will consist of a faculty or staff facilitator. Facilitators must attend an intergroup dialogue training, two lead facilitators will attend a four-day training at The National Intergroup Dialogue Institute. As lead facilitators, they will organize and lead a one-day training for all other facilitators. 
Each section will follow a similar format and have the same objectives, but the content will vary depending on the class make-up. Each class will consist of students from two different social groups that have a history plagued by inequality and/or controversy (e.g. Upper Class \& Lower Class, Men \& Women, and Cisgender \& Transgender). The goals of each section will be to encourage students to interact and learn across social groups while exploring their own perspectives and experiences and those of others. Additionally, this course will encourage students to increase their awareness of the interaction between social membership, power and privilege, develop skills to engage in dialogue and work across differences, and identify actions that will promote social justice. The class roster and topic of each class will depend on the social identity participants identified on their application. All sections will have an equal number of students representing each social group. For instance, a Men \& Women intergroup dialogue would have seven men and seven women. Likewise, the facilitators would equally represent the two groups, one man and one woman. Creating equal representation of the two groups will lessen or remove potential threats and breakdown the barriers created through the typical minority/majority frame of mind.

A residential community will be built centered on diversity, acceptance, and collaboration, the student hall will provide residents with leadership opportunities aimed to strengthen a sense of community. The mission will be to build awareness, relationships, and democratic citizenship. Students involved in the community will plan, organize, and run hall projects that promote the organization's mission. The hall projects will include hall activities (e.g. game nights, potlucks, open mic nights, movie nights), workshops (e.g. fine arts, meditation, self-reflection), and a lecture series.

\section{Evaluation}

The outcomes of the Diverse Living and Learning Community are to have students interact positively across difference, increase their cultural awareness, create a sense of belonging to the resident hall and classroom, and to develop and advance their critical thinking skills. Outcome evaluation of this project is necessary to further understand the processes and effectiveness of dialogue practices, improve on the work being done, and obtain funding. We propose a systematic and careful documentation and evaluation process of the program from beginning to end which evaluate what effect this program has on participants and whether and how dialogue achieves desired goals.

The evaluation process would be designed relate to three outcomes we plan to reach out through the program by using quantitative pre-test post-test measures. A test survey which consist of three parts: assessment of sense of belong, assessment of ethnocentrism and evaluation of critical thinking was given to all the students participate in the program at the beginning of the semester and again at the end to see how much their scores have changed since the beginning of the semester. For comparison purposes, we would invite students from one of the common resident hall as a comparison group, unlike the previous one, these data would be collected using an online survey. Students would be sent a link to the online survey and brief explanation of the study via email.

Since one of the program's outcome is helping students interact across difference and increasing cultural awareness, we would use the Ethnocentrism Scale to measure participant's awareness and attitude towards one's own group (culture) and others. One of the central concepts in understanding outgroup attitudes and intergroup relations is ethnocentrism. Sumner (1906) defined ethnocentrism as "the technical name for this view of things in which one's own group is the center of everything, and all others are scaled and rated with reference to it" (p. 13). Sumner (1906) argued that ethnocentrism nourished a group's pride and vanity while looking on outsiders, or outgroups, with contempt. 
Ethnocentrism is now recognized as a universal phenomenon experienced in all cultures. The Ethnocentrism Scale developed by James Neuliep and James McCroskey measures this concept which composed of 24 statements concerning your feelings about your culture and other cultures [21]. The second outcome we expect from the program is creating a sense of belonging in college campus. Sense of belonging refers to people's judgments of their personal sense of how much they belong to the group [11]. Sense of belonging is used as one of two primary dimensions of perceived cohesion which is theoretically defined as individual's perception of their own cohesion to a group [11]. We would use the model used as a part of Perceived Cohesion Scale created by Kenneth A. Bollen to measure participants' sense of belonging. The third goals of the project is developing or improving student's critical thinking skills. Critical thinking is deemed one of the most important and necessary skills for college graduates endeavoring to be effective contributors in the global marketplace. Critical thinking is defined as thinking that evaluates reasons and brings thought and actions in line with evaluations.

Youth may know how to access and locate, interpret, and apply information. However, if they do not invest any time in evaluating the information they use, their efforts often result in a low-quality product. Worse, failure to evaluate may result in unfavorable outcomes especially when associated with flawed information [20]. We would use critical thinking in everyday life survey created by Mincemoyer, C., Perkins, D. F., \& Munyua, C to assess students' critical thinking ability by examining the frequency of use of the following skills that are needed to think critically: reasoning, enquiry, analysis/information processing, flexibility, and evaluation. After the data collection process, descriptive statistics would be calculated for all variables, and scales would be computed for each construct. Pre-test and post-test data would be analyzed through paired t tests for the individual items of the scale and for computed scales.

In addition to the quantitative pre-test and post-test measures, we administered 10 open-ended interviews with participants to assess their experiences with the program, their most memorable activities, and their experiences from the program they might not have had otherwise. In addition, these interviews would ask to explore ways in which the program has influenced the ways they think about intergroup relations and conflict, whether it met their expectations, how they can use their learning in the future, and ways in which the program could be improved. The interviews were conducted by a trained staff member who was not one of the facilitators and took about 30 min to 1 hour to complete. Qualitative data would be transcribed and analyzed for emerging themes using content analysis and "open coding," which involves systematic review of transcripts or other textual data to capture important embedded concepts or meanings identified from the interview as the data are reviewed [31].

\section{Outcomes}

The living and learning community strives to promote diversity and inclusion among all students. When students begin their freshman year of college they have the opportunity to enroll in a one credit class and live in a culturally diverse residence hall. This class counts toward their graduation credits and helps them become more culturally competent. This program seeks to promote learning and awareness of diversity, so students can be more culturally competent throughout their college career and in life after college. The outcomes of the class are to have students interact positively across difference, increase their cultural awareness, create a sense of community in the classroom and in the residential hall, and to develop and advance their critical thinking skills and intergroup dialogue skills. 


\section{References}

[1] Antonio, A. L. (2003). Diverse student bodies, diverse faculties: The success or failure of ambitions to diversify faculty can depend on the diversity of student bodies. Academe Online.

[2] Astin, A. \& Chang, M. exerted from Who benefits from racial diversity in higher education. Retrieved May 13, 2009, from http://www.diversityweb.org/Digest/W97/research.html.

[3] Coomes, Michael D. \& DeBard, Robert (2004). Serving the Millennial Generation. San Francisco: Jossey Bass. Light, R. J. (2001). Making the Most of College Students Speak Their Minds.

[4] Maruyama, G., and Moreno, J. (2000). University faculty views about the value of diversity on campus and in the classroom. American Council on Education and

[5] Milem, J.F., Chang, M., and Antonio, A.L. (2005). Making diversity work on campus: A research-based perspective. Association of American Colleges and Universities: Washington, D.C.

[6] Paquette, M. and Schlafer, B. (2005). The many benefits of a diverse campus community. Retrieved July 5, 2009, from http://www.queensu.ca/equity/content.php?page=aaug29-2005.

[7] American College Personnel Association. (1994). The student learning imperative: Implications for student affairs. Washington, DC: Author.

[8] Antonio, A. L. (2003). Diverse student bodies, diverse faculties: The success or failure of ambitions to diversify faculty can depend on the diversity of student bodies. Academe Online.

[9] Astin, A. (1977). Student Involvement: A developmental theory for higher education. Journal of College Student Personnel. 25. 297-308.

[10] Astin, A. (1987). Achieving education excellence. San Francisco: Jossey-Bass.

[11] Bollen, K. (1990). Perceived Cohesion: A Conceptual and Empirical Examination. Social Forces 69:2, December 1990.

[12] Chickering, A. (1975). What matter in college? Four critical years revisited. San Francisco: Jossey-Bass.

[13] Coomes, Michael D. \& DeBard, Robert (2004). Serving the Millennial Generation. San Francisco: Jossey Bass.

[14] Lenning, O. \& Ebbers, L. (1999). The powerful potential of learning communities: Improving education for the future. ASHE-ERIC Higher Education Report vol. 26, no.

[15] Light, R. J. (2001). Making the Most of College Students Speak Their Minds.

[16] Marchese, T. (1994). Foreword. In C. Schroeder \& P. Mable (Eds.), Realizing the educational potential of residence halls (pp. xi-xiii). San Francisco. Jossey-Bass.

[17] McMillian, D., \& Chavis, D. (1986). Sense of community: A definition and theory. Journal of Community Psychology, 14 (1), 6-23.

[18] Meeuwisse, M., Severiens, S., \& Born, M. (2010). Learning environments, interaction, sense of belonging and study success in ethnically diverse student groups. Research in Higher Education. 51 (6), 528-545.

[19] Milem, J.F., Chang, M., and Antonio, A.L. (2005). Making diversity work on campus: A research-based perspective. Association of American Colleges and Universities: Washington, D.C.

[20] Mincemoyer, C., Perkins, D. F., \& Munyua, C. (2001). Critical Thinking in Everyday Life. derive from: https://cyfar.org/critical-thinking-everyday-life.

[21] Neuliep, J., \& McCroskey. J. (1997). The Development of a U.S. and Generalized Ethnocentrism Scale. Communication Research Reports, Volume 14, Number 4, pages 385-398.

[22] Pascarella, E. (1984). Reassessing the effects of living on campus versus commuting to college: A casual modeling approach. Review of Higher Education. 7, 247-260.

[23] Pascarella, E., Bohr, L., Nora, A., Zusman, B., Inman, P., \& Desler, M. (1993). Cognitive impacts of living on campus versus commuting to college. Journal of College Student Development. 34, 216-220.

[24] Pike, G. (1999). The effects of residential learning communities and traditional residential living arrangements on educational gains. Journal of College Student Development. vol. 40, no. 3. (p. 269-284).

[25] Paquette, M. and Schlafer, B. (2005). The many benefits of a diverse campus community. Retrieved July 5, 2009, from http://www.queensu.ca/equity/content.php?page=aaug29-2005.

[26] Schroeder, C. (1994). Developing learning communities, In C. Schroeder \& P. Mable (Eds.), Realizing the educational potential of residence halls. (pp. 165-189). San Francisco: Jossey-Bass.

[27] Schroeder, C. \& Hurst, J. (1996). Designing learning environments that integrate curricular and cocurricular experiences. Journal of College Student Development. 37, 174-181.

[28] Schroeder, C. \& Mable, P. (1994). Residence halls and the college experience: Past and present. In C. Schroeder \& P. Mable (Eds.) Realizing the educational potential of residence halls (pp. 3-21). San Francisco: Jossey-Bass.

[29] Spanierman, L., Soble, J., Mayfield, J., Neville, H., Aber, M., Khuri, L., \& De La Rosa, B. (2013). Living learning communities and students' sense of community and belonging. University of Illinois at Urbana-Champaign. 50 (3), 308-325.

[30] Spencer, M., Brown, M., Griffin, S., \& Abdullah, S. (2008). Small Group Research: Outcome Evaluation of the 
Intergroup. Project. Derive from: http://sgr.sagepub.com/content/39/1/82.

[31] Strauss, A. L., \& Corbin, J. M. (1990). Basics of qualitative research: Grounded theory procedures and techniques. Newbury Park, CA: Sage.

[32] Sumner, W. G. (1906). Folkways. Boston: Ginn.

[33] Tinto, V. (2003). Learning better together: The impact of learning communities on student success. Higher Education Monograph Series. Syracuse University. 